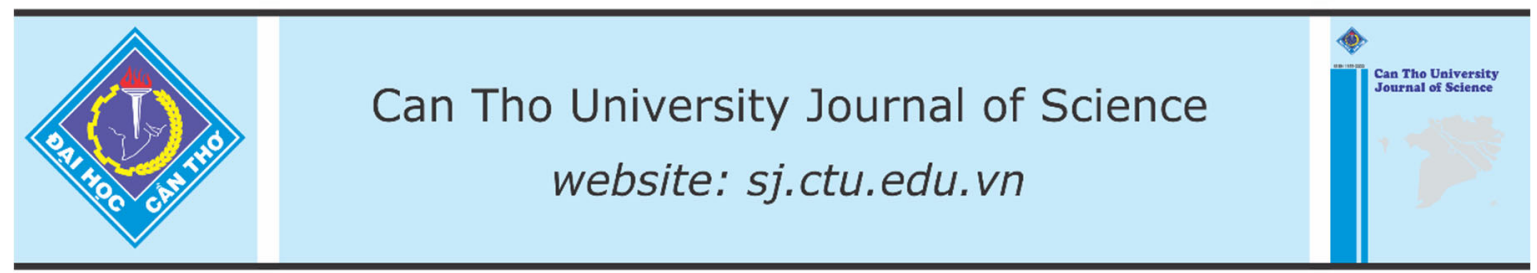

DOI: $10.22144 /$ ctu.jen.2019.006

\title{
Towards a new open educational resource model using OKMindmap
}

\author{
Bui Le Diem ${ }^{1 *}$, Yong-Gi Kim², Bui Le Diem Trang ${ }^{3}$ and Won $\mathrm{Ho}^{4}$ \\ ${ }^{I}$ School of Education, Can Tho University, Vietnam \\ ${ }^{2}$ AI Lab, Gyeongsang National University, Korea \\ ${ }^{3}$ School of Education, An Giang University, Vietnam \\ ${ }^{4}$ Electrial Engineering Department, Konju National University, Korea \\ ${ }^{*}$ Correspondence: Bui Le Diem (email: bldiem@ctu.edu.vn)
}

\section{Article info.}

Received 18 Apr 2018

Revised 17 May 2018

Accepted 29 Mar 2019

\section{Keywords}

ICT in education, OER, Big

Book, OKMindmap,

WebQuest

\begin{abstract}
Mind Maps are a useful teaching and learning tool. They could enable the skills of communication, collaboration, critical thinking and creativity which are identified as super skills being required for success in the $21^{\text {st }}$ century. This paper suggests using OKMindmap to create a new open educational resource (OER) model called Big Book as an innovative educational method. The book was intended as an online collaborative learning environment where multiple sources of information such as video clips, images, sounds, texts and hyperlinks could be added as nodes of OKMindmap. It was trialed with the tenth graders at Teacher Practice High School of Can Tho University for one year. The results of the trial were positive. The students were interested in this new mode of learning since they could create their own Big Book by gathering information available on the web or design their own study plan which can be easily shared. The findings point to the feasibility of creating a Big Book for Vietnamese learners as the design of the Big Book was made easier and more affordable than ever in the age of technology.
\end{abstract}

Cited as: Diem, B.L., Kim, Y.G., Trang, B.L.D. and Ho, W., 2019. Towards a new open educational resource model using OKMindmap. Can Tho University Journal of Science. 11(1): 42-48.

\section{INTRODUCTION}

According to United Nations Educational, Scientific and Cultural Organization (UNESCO), the development of information and knowledge determines the development of modern societies. Having sufficient ICT (information and communication technology) skills is thus essential for labor to be able to manage information development and create new knowledge. Educational reform is required in education systems worldwide with a strong emphasis on the role of the teachers. Regarding this issue, UNESCO advises that ICT education is not limited to the teachers who are knowledgeable or able to transmit the knowledge of ICT to their students. What essential is their awareness of their roles in equipping the students with the four skills including collaboration, cooperation, problem solving and creative thinking through the use of ICT (Thompson et al., 2003). With such a reform, the education systems are likely to train qualified citizens who are able to cope with emerging demands in the modern societies. This research was motivated by this call from UNESCO.

\section{LITERATURE REVIEW}

Since its birth in 1970s by Tony Buzan, a mindmap has been regarded as an effective organizational 
thinking tool. In recent years, mind Maps have have become a popular teaching tool and being developed along with the advent of technology. Following mindmap is OKMindmap, a free online mind mapping tool, created to support the mind mapping process. OKMindmap allows its users to collect and connect information from various online sources. Sources such as images, video clips, documents and websites can be linked in mind map nodes. Users can access and update their mind maps for their own purposes. One notable benefit of OKMindmap is its ability to enable the learners to share information, which is supposed to enhance collaboration and facilitate the learning process (Won, 2015).

OKmindmap is an innovative tool for drawing a mindmap. Using mind mapping with OKMindmap requires the combination of higher-order thinking skills and technological advances. As such, the use of OKMindmap is believed to be able to promote the development of four super skills including communication, collaboration, critical thinking and creativity (Gregg and Saha, 2007). These are considered as essential skills to be possessed by the $21^{\text {st }}$ century citizens. As for the learners to possess those four skills, teachers play a more crucial role than ever. They are expected to improve their teaching methods (Fun and Maskat, 2010), and one of the ways is to harness the advances of information technology (Rohatgi et al., 2016).

Although mindmapping has been claimed to be a powerful thinking tool and OKMindmap has been developed to facilitate mindmapping, little research has been conducted into the use of OK-mindmap in education. This study seeks to address this gap. It explored the effect of OER model called as Big Book in OKMindmap style on high school students' learning method.

The idea of creating 'a book' in the form of an OKMindmap page as found in this link http://bit.ly/2aWlsQ1 is to develop an open educational resource. This book enables the learners to manage their own studies or frequently update their own book in order to serve their learning and then life-long learning needs. This can be done almost anywhere and anytime provided that the learners have access to internet-connected smart phones or laptops (Baborska-Narozny et al., 2016).

The development of this system requires the learners' ability to use OKMindmap and some basic computer skills as required by UNESCO. It is therefore feasible to cater the idea to all kinds of learners. The completed books can be shared within a class, a group of classes or a school. The books can then be shared on the social networks, which can be of benefit to a wider population. This mode of learning is believed to be able to promote a more effective learning method which can encourage creativity as opposed to the method which promotes memorization or rote learning. The books resulted from the use of OKMindmap can be analysed to identify individual capabilities. The results can inform the teachers of the actions they should take in order to support their future career choice.

In conclusion, as mentioned above, it is hypothesized that the idea of creating 'a Big Book' can be realised by harnessing the availability of OKMindmap and ICT skills. This motivated this study to be conducted.

\section{RESEARCH METHODOLOGY}

The aim of this research study was to explore the effect of OER model called as Big Book in OKMindmap style on high school students' learning method. For this purpose, the following research questions were investigated:

(1) How was the idea of creating a "Big Book" using OKMindmap implemented by high school students in Viet Nam?

(2) What did the students perceive about their experience of using OKMindmap to create their own book?

Enhancing the teaching and learning quality is a priority Teacher Practice High School of Can Tho University. One of its commitments is to maximize the power of ICT education, which is associated with quality improvement in teaching ICT at this school. As an ICT teacher, the first author who is also a teacher at this school, has implemented an innovative idea in teaching Informatics to a group of high school students. On the basis of the benefits that OKMindmap offers, an experiment of creating "a book of knowledge" through the use of OKMindmap was implemented. Following the WebQuest method, the students collected the information available on the web to create their own book. Then the mapping techniques using this free drawing tool were employed to create the 'books'.

\subsection{Participants}

Forty-two of the tenth graders at Teacher Practice High School of Can Tho University involved in the study. These students were among those who were taking Informatics as a subject in the curriculum. Learning how to use OKMindmap is one of the subject areas required in the syllabus and taught over a two-week period. The students were first introduced to OKMindmap. They then created their mindmaps for self-study and group study under the 
teacher's instructions. Each individual student was then required to create a personal mind map to serve their own learning purpose. They started mind mapping their ideas and then collecting knowledge and information available on the web to create a book for themselves.

\subsection{Data collection and analysis}

Data were collected from two sources including:

(1) The "Big Books" created by the students were collected for analysis. These books were submitted to the teachers as a completion of an end-of term assignment. A collection of 42 books were analysed. Themes were drawn from the collection based on the underlying ideas embodied in the books.

(2) The students were invited to complete an online survey in which they reflected their experience of using OKMindmaps to create their own books. The survey included open questions which elicited perceptions and allowed for detailed responses. The data was then analysed inductively. This process involves checking and reviewing the data to identify the themes. The emerging themes reduced to three main themes which are discussed in the result section.

\section{RESULTS}

\subsection{Student-created books}

Results from the analysis of 42 "Big Books" from 42 students participating in this research have showed that the students have created their own books successfully using OKMindmap. Each book has its own characteristics and shows different ideas and expectations. Across the "Big Books", students presented different topics that they wanted to know and share. Those topics shown in the "Big Books" illustrated different learning needs including the consolidation of knowledge of school subjects, the hobbies such as music and the expectation to share experiences and future plans. All of the "Big Books" were lively designed and filled with many links about music, images or video clips which are available on the internet (Figure 1). To discover these "Big Books" further, some striking topics that the students used in their books were introduced as follows:

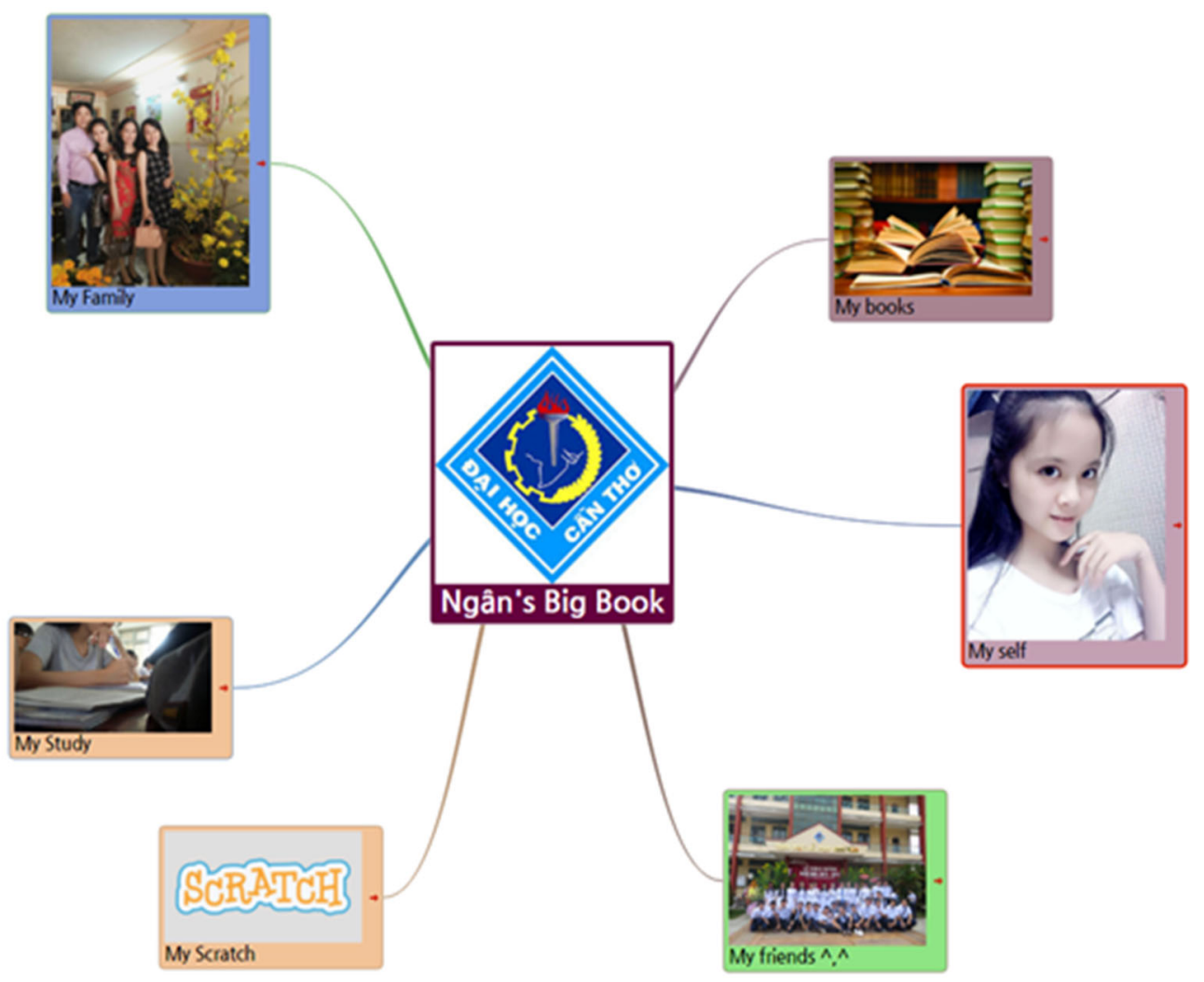

Fig. 1: A sample of a complete student-created book http://bit.ly/2aVSb8n

Firstly, the students were interested in creating a book serving the demand of synthesizing knowledge from school subjects. They linked a number of different subjects together and presented their main contents in form of mind maps (Figure 2). It is clear 
that they were able to synthesize all knowledge they learnt in the book. That knowledge is not only school subject knowledge, but also the knowledge about other subjects serving self-study process on the internet. The procedure of studying, selecting and evaluating information on the internet will primarily help students develop their critical thinking skill. Moreover, the process of searching for ways to create mind maps indirectly helps the students develop their creative-thinking skill. More importantly, having an own book to share with each other is a good way to help them recognize the importance of collaborating and sharing. This is a key and also the shortest way to help them seek knowledge and develop their life skills.

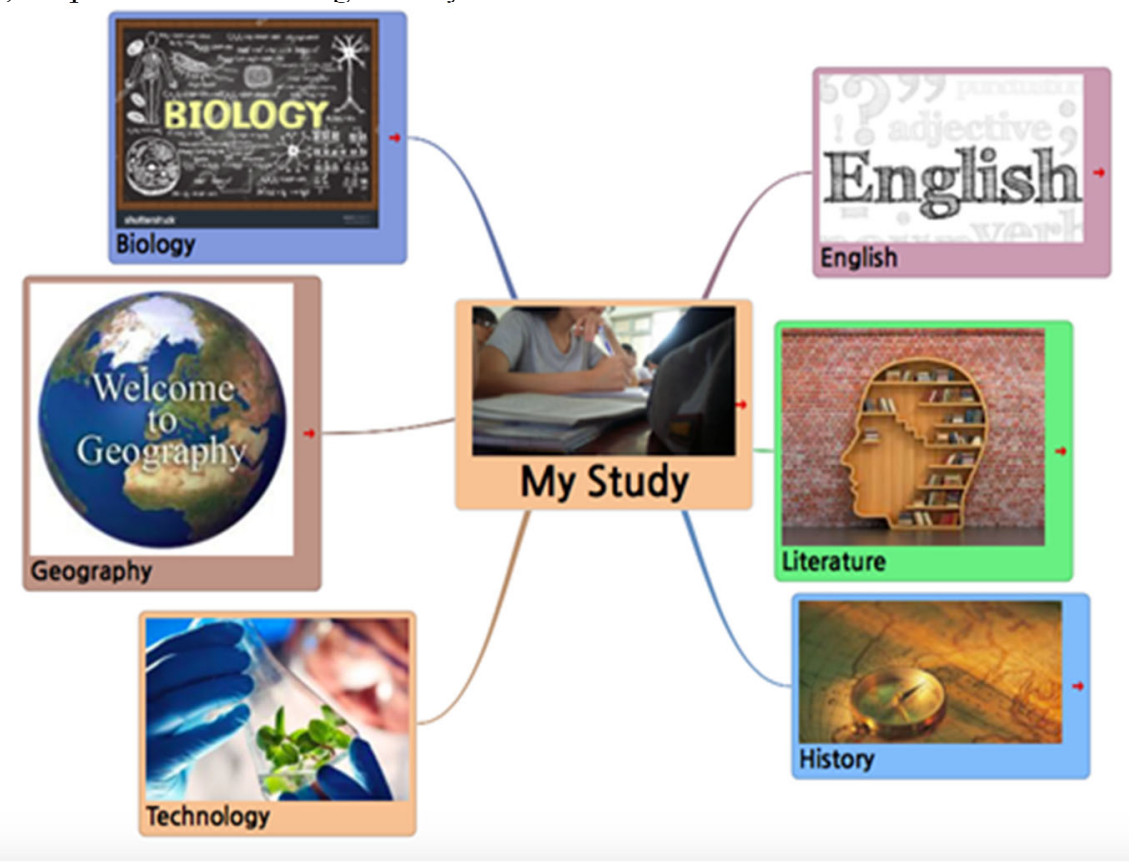

Fig. 2: Mind mapping of subject knowledge http://bit.ly/2b0rcIP

Secondly, the book is also a good place for the students to discover and expand their knowledge about a certain field that they want to know. Sharing is an occasion for students to show their expectation and exchange information with their friends.
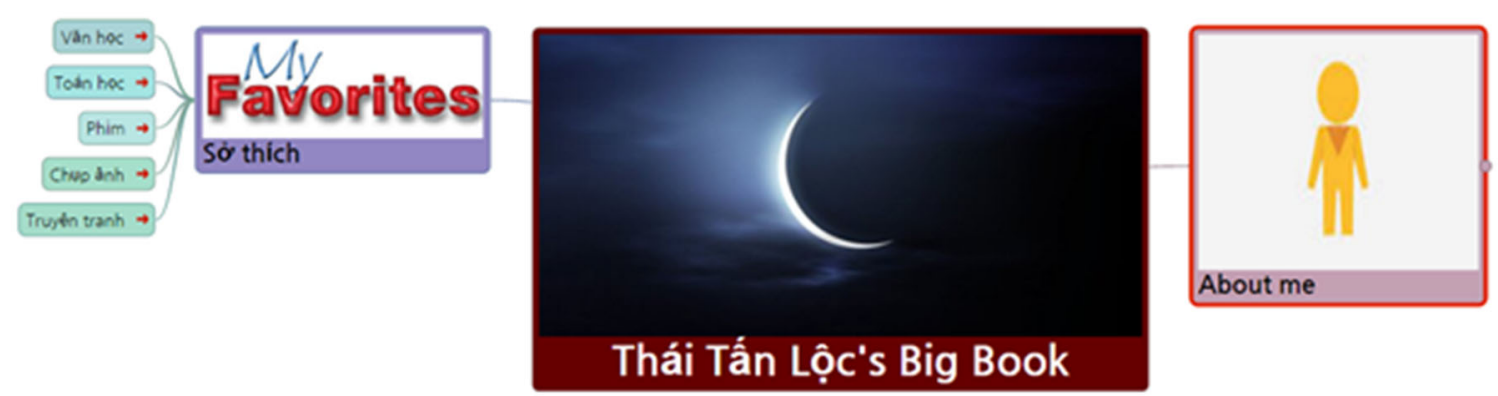

Fig. 3: Mind mapping of personal interests http://bit.ly/2b2K0Hm

Two topics that interested the students the most have been presented. These books were then shared among friends in groups and with the whole class (Figure 4). This enhanced their solidarity and cooperation. The sharing activities helped them develop their communicative skills. It is believed that the development of the "Big Book" benefits the development of four skills mentioned above. These skills were recognized by their thanks to the obtained results of a survey to get students' opinions about creating Big Book. 


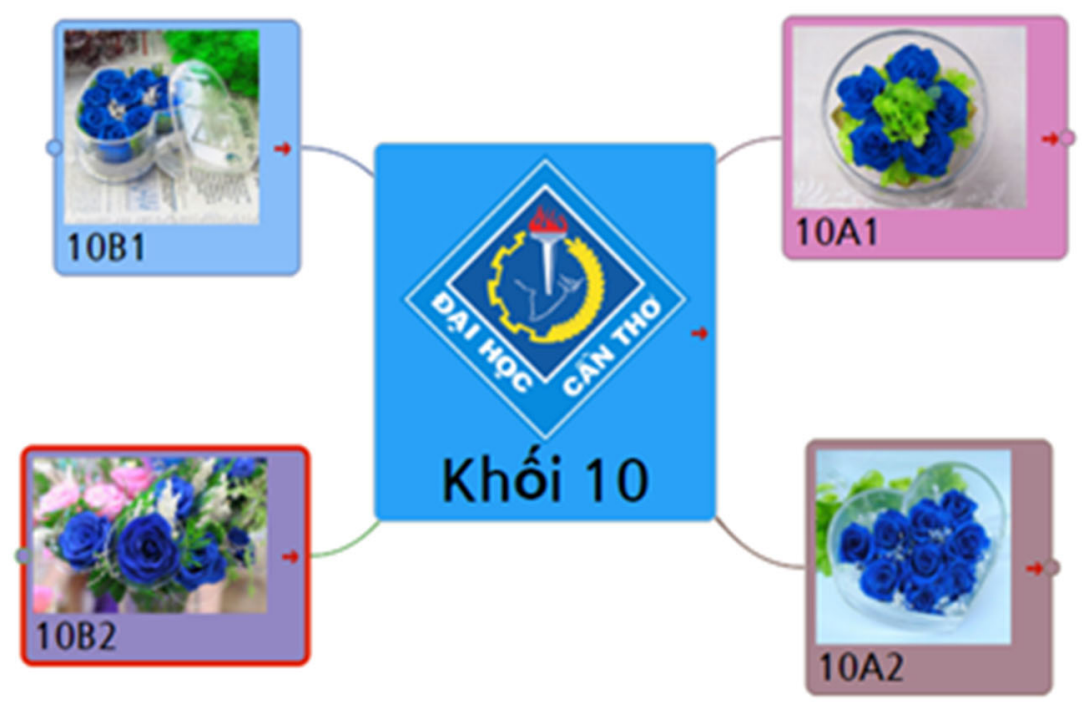

Fig. 4: A completed book to share among the Grade 10 students http://bit.ly/2aWlsQI

\subsection{Benefits of creating the books in form of OKMindmap}

The survey results showed that most students highly appreciated the use of OKMindmap. Their opinions centred on three main issues: practicality of OKMindmap, increasing motivation and creativity and enhancing the study outcomes.

\subsubsection{Practicality of OKMindmap}

The majority of students (30 out of 42 ) considered that the application of OKMindmap carried highly practical applicability. They believed that OKMindmap is a useful tool not only for learning but also for enhancing knowledge through its capacity of creating of "a house of knowledge", "a private book", or "a treasure of knowledge" or "an extremely diverse world". Thanks to this tool, students can easily "seek knowledge and write down what they like". A representative comment is as follows:

"I see that the OKMindmap application is really interesting and useful. It helps me synthesize my knowledge. Furthermore, it works as an on-line mind mapping tool in general - an effective way of learning being applied widely in developed countries. OKMindmap not only enables me to consolidate systematic knowledge about my study, but also helps me build an extremely diverse world for myself. It is a house of knowledge, a house of music, and especially it is free to use."

In addition to using OKMindmap to "create a treasure of knowledge" as a comment from a student, they also regarded it as a chance to share and exchange knowledge as well as other interesting things in life.

"OKMindmap has been and will be an extremely useful tool that helps me build a house of knowledge for myself. It also helps me share useful things in my life. I can also share and learn new knowledge. In general, it is different from the old and backward programs like Pascal, which does not fit with the modern world. The application of OKMindmap in learning can receive many supports including mine".

Related to this issue, another interesting opinion is that besides equipping knowledge for themselves, the 'Big Book' also "helps to keep record of current knowledge to meet the communication requirements of the surrounding world". The students also considered the use of OKMindmap "helps [them] save what [they] have learnt and discovered; help [them] possess a private and useful book."

Finally, in relation to this practical issue, three students thought that the use of OKMindmap to mind map and share knowledge helps them save time and consult different sources of knowledge thanks to sharing and exchanging. A representative comment is:

"It helps me save time looking for information and reading books or other applications, especially in studying, it is a trusted application. It helps me have more chances to consult and gain much useful knowledge as well." 


\subsubsection{Increasing motivation and creativity}

In addition to the practicality of OKMindmap in collecting, sharing and recording knowledge, many students $(10 / 42)$ commented that the use of OKMindmap enhances learning motivation indirectly. They considered that mindmapping useful knowledge of many different subject aspects on a 'Big Book' motivated them to learn. One typical opinion is:

"Studying with OKMindmap is very useful because I can save many useful documents or other useful and interesting things. I can update my book easily without being afraid of losing them over time. This interests me and I do not get bored with lessons from the printed books as before."

Moreover, creating a 'Big Book' by using OKMindmap has promoted students' learning, especially helping them bring into play their creativity. This helps form one of the four skills - creativity - as mentioned above.

\section{"Help me to be more creative" \\ "Support me more in creativity" \\ "Help my creativity fly away"}

\subsubsection{Enhancing learning outcomes}

The use of OKMindmap in learning is considered to help students enhance their learning results in many different school subjects. Many students said that this was due to a transition from a traditional method to a creative and interactive method. Helping students have the ability to discover diverse knowledge on the internet and save them systematically is a good way to help students "learn better based on collected information". Many students said that this method enhanced their engagement in their learning of school subjects, especially in Informatics.

"OKMindmap helps me save many useful and interesting things, engage me in learning Informatics which focus mainly on practices and I do not need to learn lots of boring theories".

"I think that in the age of modern science, using OKMindmap is very helpful and assist me in learning Informatics and approaching modern world."

In addition to helping students learn Informatics better, using OKMindmap also helps them learn other school subjects such as English better. Specifically, students thought that searching and reading information on the internet help them "enhance their vocabulary and grammar in English". In short, the idea of creating Big Book can motivate the students in their learning and help them find better learning methods for not only Informatics but also other school subjects.

\section{DISCUSSION}

The findings of the study showed that the idea of creating Big Book to serve the learning purposes has been successfully conducted by Vietnamese high school students. It can be shown through the books that they created, and importantly through their perceptions. Most students admitted the importance of discovering available data on the internet. They were interested in knowing how to collect and save different sources of information, serving their study purposes, their long-life learning needs and their personal developments. From their opinions, it can be seen that they had many positive changes in their mind regarding studying as well as learning methods. They begin recognizing the importance of selfstudy through doing research via internet. As such, studying does not stop at mastering hard skills or subject knowledge, but developing soft skills as well.

The model is expected to expand to a larger population of students at Can Tho University. By doing this, every student can own a book of knowledge and are encouraged to share their books to their classmates, schoolmates or friends from remote areas via the social networks. Everybody, hence, has an opportunity to learn for their whole life. This "Big Book" will be used as an open courseware as well as a valuable data source, which is as a base to build WebQuest library in form of OKMindmap (HajAlizadeh and Khorasani Anari, 2016). It is hoped that this model can connect education students and teachers in building a bank of WebQuest exercises (Averkieva et al., 2015). Teachers across the country can use the same WebQuest library for teaching, and students' products will be created by using OKMindmap. These kinds of products containing student-created data in form of documents, videos, or projects could be easily programmed using simple programming languages such as Scratch of Massachusetts Institute of Technology (Mironova et al., 2015).

Another potential is that on the basis of OKMindmap products, a new model of assessment using Data mining in education (Shen and Kuo, 2015) can be built. This form of assessment can identify both weaknesses and strengths of the learners so that suitable consultancy can be given to individual learners. By so doing, it is hoped that pupils can achieve more success. 


\section{CONCLUSIONS}

The idea of creating "a Big Book” using OKMindmap plays an important role in learning and teaching in this internet-connected world. With an internetconnected device such as a laptop, a computer or a smart phone, the learners and teachers can mind map what they want to learn and teach in form of a book. A bigger book can then be created by a variety of contributions. This is expected to promote the development of the four skills necessary for the $21^{\text {st }}$ century including cooperation, collaboration, critical thinking and creativity.

It is proposed that the "Big Book" model is expanded and specialized. For instance, medical students and doctors in hospitals can be encouraged to build a "Big Book" to help support the community. Some other "Big Book" models can be about agriculture, industry, sex education, road safety education, environmental education and gender equality education. By doing this, the book of knowledge built from brainpower of many people will be practical and have the most positive impact on social life.

\section{REFERENCES}

Averkieva, L., Chayka, Y., and Glushkov, S., 2015. Webquest as a tool for increasing students' motivation and critical thinking development. Procedia Social and Behavioral Sciences, 206: 137-140.

Baborska-Narozny, M., Stevenson, F., and Ziyad, F. J., 2016. User learning and emerging practices in relation to innovative technologies: A case study of domestic photovoltaic systems in the UK. Energy Research \& Social Science, 13: 24-37.
Fun, C. S., and Maskat, N., 2010. Teacher-centered mind papping vs student-centered mindmapping in the teaching of accounting at Pre-U level - an action research. Procedia - Social and Behavioral Sciences, 7: 240-246.

Gregg, J., and Saha, S., 2007. Communicative competence: a framework for understanding language barriers in health care. Journal of General Internal Medicine, 22 (2): 368-370.

HajAlizadeh, K., and Khorasani Anari, Z., 2016. Effectiveness of teaching through brainstorming on the students' critical thinking and motivation. Academic Journal of Psychological Studies, 5(2): 183-192.

Mironova, O., Amitan, I., Vendelin, J., Vilipõld, J., and Saar, M., 2015. Object-oriented programming for non-IT students: starting from scratch. International Journal of Engineering Pedagogy (IJEP), 5(4): 22-28.

Rohatgi, A., Scherer, R., and Hatlevik, O. E., 2016. The role of ICT self-efficacy for students' ICT use and their achievement in a computer and information literacy test. Computers and Education, 102: 103-116.

Shen, C., and Kuo, C.-J., 2015. Learning in massive open online courses: Evidence from social media mining. Computers in Human Behavior, 51: 568-577.

Thompson, S. D., Martin, L., Richards, L., and Branson, D., 2003. Assessing critical thinking and problem solving using a Web-based curriculum for students. The Internet and Higher Education, 6(2): 185-191.

Zheng, L., Yang, J., Cheng, W., and Huang, R., 2014. Emerging approaches for supporting easy, engaged and effective collaborative learning. Journal of King Saud University - Computer and Information Sciences, 26(1): 11-16.

Won, H., 2015. Innovative collaborating environment building using OKMindmap embedding node capability. Indian Journal of Science and Technology, 8(S9): 208-212 